\title{
Efeito da solução de ácido acetilsalicílico e de ácido acético em fígado de coelhos ${ }^{1}$
}

\author{
Effect of acetylsalicylic acid and acetic acid solutions in liver of rabbits
}

\author{
Rogério Saad-Hossne², René Gamberini Prado ${ }^{2}$, William Saad Hossne ${ }^{3}$ \\ 1. Trabalho realizado no Laboratório de Cirurgia Experimental do Depto de Cirurgia e Ortopedia da Faculdade de Medicina de Botucatu. \\ 2. Professor Doutor do Departamento de Cirurgia e Ortopedia da Faculdade de Medicina de Botucatu - UNESP. \\ 3. Professor Emérito da Faculdade de Medicina de Botucatu - UNESP.
}

\begin{abstract}
RESUMO
Objetivo: Analisar os efeitos das soluções de aspirina e de ácido acético, in vivo, em fígado de coelhos sadios, verificando o efeito histolítico e o resultado anatomo-patológico das lesões e eventuais alterações bioquímicas hepáticas. Métodos: Utilizou-se 80 coelhos, divididos em 2 protocolos experimentais (1 e 2), subdivididos em 5 grupos cada, sendo os mesmos submetidos a laparotomia mediana, com injeção de $0,4 \mathrm{ml}$ da solução de aspirina (2,5 e 5,0\%), de ácido acético (2,5 e 5,0\%) e solução salina; o sacrifício ocorreu apos 24 horas (protocolo1) e 14 dias (protocolo 2); avaliou-se o peso, evolução clinica, dosagens bioquímicas, cavidade abdominal e torácica e microscopia do fígado. Resultados: Não foram observadas alterações na evolução clinica, peso e nas dosagens bioquímicas, apenas elevação da AST e ALT no grupo 24 horas(Protocolo 1). À macroscópica mostrou que nos animais tratados, em ambos os grupos, a presença de lesão hepática localizada na área infiltrada, correspondente a necrose (24 horas) e fibrose (14 dias). Conclusão: Ambas as soluções (aspirina e ácido acético) acarretaram destruição localizada do órgão substituída por fibrose apos 14 dias.
\end{abstract}

Descritores: Carcinoma. Ácido Acetilsalicílico. Ácido Acético. Fígado. In vitro. Coelhos.

\begin{abstract}
Purpose: In the present work, 2.5\% and 5\% acetyl salicylic acid solution and acetic acid solutions were tested in vivo. Methods: In all tests control animals were used and given salt solution. 80 male rabbits were employed and randomly distributed among the different experimental groups. Results: When injected in the liver of healthy rabbits (in vivo), both solutions produced localized destruction (coagulative necrosis) of the hepatic parenchyma in 24 hours. After 14 days, these lesions either disappeared or were replaced by mild scars (fibrosis). The lesions were not followed by clinical alterations and the only observed biochemical alteration was an increase in the amount of alanine amino transferase after 24 hours. Conclusion: In vivo, the effects of both concentrations $(2.5 \%$ and $5 \%)$ were the same, although more intense at 5\%. The experimental results support the eventual clinical application of the acetyl salicylic acid solution and acetic acid solution in the treatment of liver metastases.
\end{abstract}

Key words: Carcinoma. Aspirin. Acetic Acid. Liver. In vitro. Rabbits.

\section{Introdução}

A preocupação humana com o câncer justifica-se pela sua alta incidência mundial que, mantidas as proporções e as características de cada país, tornam-no a segunda causa de morte da população adulta ${ }^{1}$; em nosso país as neoplasias são a segunda causa de morte em indivíduos com mais de 40 anos e a terceira causa de morte em todas as faixas etárias. As neoplasias são responsáveis por aproximadamente $16 \%$ dos óbitos, o que significa aproximadamente 110.000 mil mortes por ano ${ }^{2}$; as neoplasias mais freqüentes são as de pele, mama, pulmões, estômago, colo uterino, próstata e cólon e reto, que, somadas, totalizam 157.000 casos novos/ano ${ }^{2}$.
Os principais fatores de prognóstico e recidiva das neoplasias são o comprometimento linfático, a recorrência local, o estadiamento e principalmente a presença de metástases à distância; um dos órgãos mais freqüentemente atingidos é o fígado, onde a terapêutica reveste-se de algumas limitações, tais como número de metastases e sua localização.

As principais modalidades terapêuticas hoje empregadas para o tratamento das metástases hepáticas são: as ressecções cirúrgicas, as ligaduras arteriais, a embolização e a quimioterapia, os métodos de ablação (laser, radiofreqüência, crioterapia, hipertermia, micro-ondas e substâncias necrotizantes 
e citolíticas) e a terapia genética.

A ressecção cirúrgica, principal modalidade terapêutica, é a única que, até o momento, oferece possibilidade de cura; porém a porcentagem de pacientes passíveis de intervenção cirúrgica $(10-15 \%)$ é baixa ${ }^{3}$.

Dentre os métodos paliativos, destaca-se o ablativo, onde se utilizam substâncias citolíticas e necrotizantes como o álcool, ou outros métodos, como a crioterapia, radiofreqüência, laser e micro-ondas para a destruição localizada da lesão; este métodos são reservados principalmente aos casos inoperáveis.

Face a estas dificuldades e características da terapêutica das metástases hepáticas, novos tratamentos necessitam ser desenvolvidos, visando uma boa taxa de eficácia, baixo custo, baixa freqüência de efeitos colaterais e de fácil execução.

Em 1996, realizamos ${ }^{4}$ estudo analisando os efeitos da solução composta por ácido acético, glicerina, fenol e água destilada sobre o tumor ascítico de Ehrlich, in vitro e in vivo; observamos que esta solução causa in vitro a morte (inviabilidade) das células tumorais e in vivo a injeção intraperitoneal da solução reduz o número de células tumorais e eleva o número de células inflamatórias em suspensão no líquido ascítico $^{4}$.

Tendo em vista este efeito observado, nos propusemos à analisar os possíveis efeitos de um ou mais componentes da solução isoladamente; revendo a literatura, não encontramos nenhum trabalho com referência ao uso do ácido acético e um dos seus derivados, o ácido acetilsalicílico, em tumores experimentais.

Diante dos resultados anteriormente obtidos e desta consideração, decidimos avaliar os efeitos da solução de ácido acetilsalicílico e da solução de ácido acético em fígado de animais sadios.

\section{Objetivo}

Analisar os efeitos da solução bicarbonatada de ácido acetilsalicílico e da solução aquosa de ácido acético, in vivo, no fígado de coelhos sadios verificando: 1) se as soluções quando injetadas no fígado, provocam de imediato ( 24 horas) a destruição localizada do órgão (efeito histolítico), 2) Qual a evolução histopatológica das lesões após 2 semanas (14 dias) e 3) Verificar se ocorrem alterações clínicas e bioquímicas relacionadas à função hepática.

\section{Métodos}

\section{Animais}

Foram utilizados 80 coelhos machos albinos com 6 a 9 semanas de vida, pesando entre 1400 e 2500 gramas. Os animais foram submetidos a jejum prévio de 6 horas antes dos procedimentos, recebendo água ad libitum.

\section{Técnica cirúrgica e anestésica}

A técnica utilizada para a retirada e injeção da solução teste no tecido hepático foi a laparotomia mediana supra-umbilical, com fechamento por planos com fio inabsorvível (mononylon 4-0). Utilizamos o pentobarbital sódico a 3\% na dose de $30 \mathrm{mg} / \mathrm{kg}$ endovenoso para a anestesia. O sacrifício ocorreu pela injeção letal de anestésico. Procedemos à injeção $0,4 \mathrm{ml}$ das diferentes soluções no lobo esquerdo do fígado, através da laparotomia.

\section{Soluções teste}

As drogas testadas foram o ácido acético (solução aquosa) a $2,5 \%$ e $5 \%$, e o ácido acetilsalicílico. Para a obtenção das soluções nas concentrações desejadas de ácido acetilsalicílico foi feita a diluição de $500 \mathrm{mg}$ de ácido acetilsalicílico em $20 \mathrm{ml}$ e $10 \mathrm{ml}$ de bicarbonato de sódio a $10 \%$ respectivamente, formando a solução bicarbonatada de ácido acetilsalicílico. As soluções foram preparadas 2 minutos antes do seu uso.

A dose utilizada destas drogas foi de 0,3 a $0,5 \mathrm{ml}$, sendo que como controle utilizou-se solução salina também no mesmo volume.

\section{Peso e evolução clínica dos animais}

Os animais foram pesados antes de cada procedimento, durante os protocolos.

Foi avaliada a evolução clínica dos animais através de parâmetros objetivos como recuperação pós-cirurgia, alimentação e atividade, sendo então classificados subjetivamente em evolução "boa", "regular" e "ruim".

\section{Dosagens bioquímicas séricas}

Antes de cada procedimento, dentro de cada protocolo, os animais foram submetidos a punção venosa periférica com agulha $25 \times 7$ e retirados $5 \mathrm{ml}$ de sangue.

Foram analisadas as seguintes variáveis bioquímicas: glicemia, fosfatase alcalina (FA), gama glutamil transferase (GGT), aspartato aminotransferase (AST), alanina aminotransferase (ALT).

\section{Exame macroscópico da cavidade abdominal e} torácica

Foi avaliado o aspecto macroscópico das cavidades abdominal e torácica (aspecto da serosa e dos órgãos) após o sacrifício do animal.

\section{Exame microscópico do fígado}

O lobo hepático esquerdo foi preparado em pararfina e a análise das lâminas foi realizada em microscópio ótico de campo claro, de forma aleatória e sem o conhecimento prévio do pesquisador quanto ao protocolo correspondente. 


\section{Análise estatística dos resultados}

Foi realizado estudo da freqüência relativa (porcentagem) de células viáveis, com base nas médias obtidas nas repetições.

\section{Protocolos}

\section{PROTOCOLO 1}

Os animais foram sacrificados 24 horas após o tratamento, as dosagens bioquímicas e a aferição do peso foram realizadas em dois momentos: antes da injeção das soluções e após 24 horas de tratamento.

Foram criados 5 grupos experimentais com quarenta animais ao todo (oito animais por grupo).

Grupo A - Solução salina (SS)

Grupo B - Ácido Acetilsalicílico 2,5\% (AAS 2,5\%)

Grupo C - Ácido Acetilsalicílico 5,0\% (AAS 5\%)

Grupo D - Ácido Acético 2,5\% (AA 2,5\%)

Grupo E - Ácido Acético 5,0\% (AA 5\%) (sorteio).

A distribuição dos animais nos grupos foi aleatória

\section{PROTOCOLO 2}

Foi delineado para avaliação do efeito das soluções testes no tecido hepático de coelhos sadios (sem tumor), 14 dias após a injeção das mesmas no lobo esquerdo do fígado.

Foram criados também 5 grupos experimentais com quarenta animais ao todo (oito animais por grupo).

Grupo F - Solução salina (SS)

Grupo G - Ácido Acetilsalicílico 2,5\% (AAS 2,5\%)

Grupo H - Ácido Acetilsalicílico 5,0\% (AAS $5 \%$ )

Grupo I - Ácido Acético 2,5\% (AA 2,5\%)

Grupo J - Ácido Acético 5,0\% (AA 5\%)
A distribuição dos animais nos grupos foi aleatória (sorteio).

\section{Resultados}

\section{PROTOCOLO 1}

\section{Evolução clínica}

Em todos os grupos, os animais apresentaram boa evolução clínica, não ocorrendo nenhum óbito.

\section{Evolução ponderal}

Observou se que, nos 5 grupos, todos os animais evoluíram com ganho de peso. Não houve diferença estatisticamente significante em nenhum dos momentos estudados.

\section{Dosagens bioquímicas}

Glicemia, Fosfatase Alcalina (FA) e Gama Glutamiltransferase (GGT)

Todos os valores das dosagens de glicemia, fosfatase alcalina e gama-gt estavam dentro dos valores de referência, não havendo diferença estatisticamente significante em nenhum das dosagens nos diferentes momentos estudados.

\section{Alanina Aminotransferase (ALT) e Aspartato Ami- notransferase (AST)}

A análise dos achados demonstra que todas as dosagens nestes grupos estão dentro dos valores de referência; houve porém, uma elevação progressiva nos valores de ambas as dosagens no decorrer do tempo, havendo diferença estatisticamente significante nas dosagens de ALT (Tabela 1).

TABELA 1 - Média dos valores da dosagem sérica de ALT (U/L) no grupo sem tumor, nos momentos 0 e 24 hs, teste de Tukey (DMS), coeficiente de variação (CV) e teste F. Protocolo 1

\begin{tabular}{|c|c|c|}
\hline \multirow[b]{2}{*}{ Tratamentos } & \multicolumn{2}{|c|}{ Momentos } \\
\hline & 0 & 24 hs \\
\hline $\mathrm{S}$ & 29 a & $31 \mathrm{a}$ \\
\hline AAS $2,5 \%$ & 27 a & $42 a b$ \\
\hline AAS 5\% & 30 a & $42 a b$ \\
\hline AA $2,5 \%$ & 29 a & $46 \mathrm{~b}$ \\
\hline \multirow[t]{4}{*}{ AA 5\% } & $31 a$ & $49 \mathrm{~b}$ \\
\hline & DMS= 11,9 & $\mathrm{DMS}=11,8$ \\
\hline & $C V=28,2$ & $C V=19,7$ \\
\hline & $\mathrm{F}=0,28(\mathrm{NS})$ & $\mathrm{F}=5,59^{* *}$ \\
\hline
\end{tabular}

Médias seguidas da mesma letra na vertical não diferem entre si, pelo teste de Tukey, ao nível de 5\% de significância. 

dominal

Aspectos macroscópicos da cavidade torácica e ab-

Não se observaram quaisquer alterações na cavidade torácica dos animais nos diversos grupos no momento do sacrifício.

Os achados no grupo tratado com solução salina (Grupo A) não evidenciaram quaisquer alterações na cavidade abdominal; quanto ao parênquima hepático, foi possível observar somente área puntiforme de coloração branca, correspondente ao local da punção.

Nos grupos tratados com as soluções teste, em todos os animais foram observadas lesões hepáticas, caracterizadas por áreas de coloração diferente do tecido hepático (brancoavermelhada), bem evidentes, com contornos e limites definidos, com diâmetro variável entre 0,6 e 1,0 cm, levemente endurecidas à palpação, sem aderências locais (Figura 1). No restante da cavidade abdominal, não foram identificadas alterações.

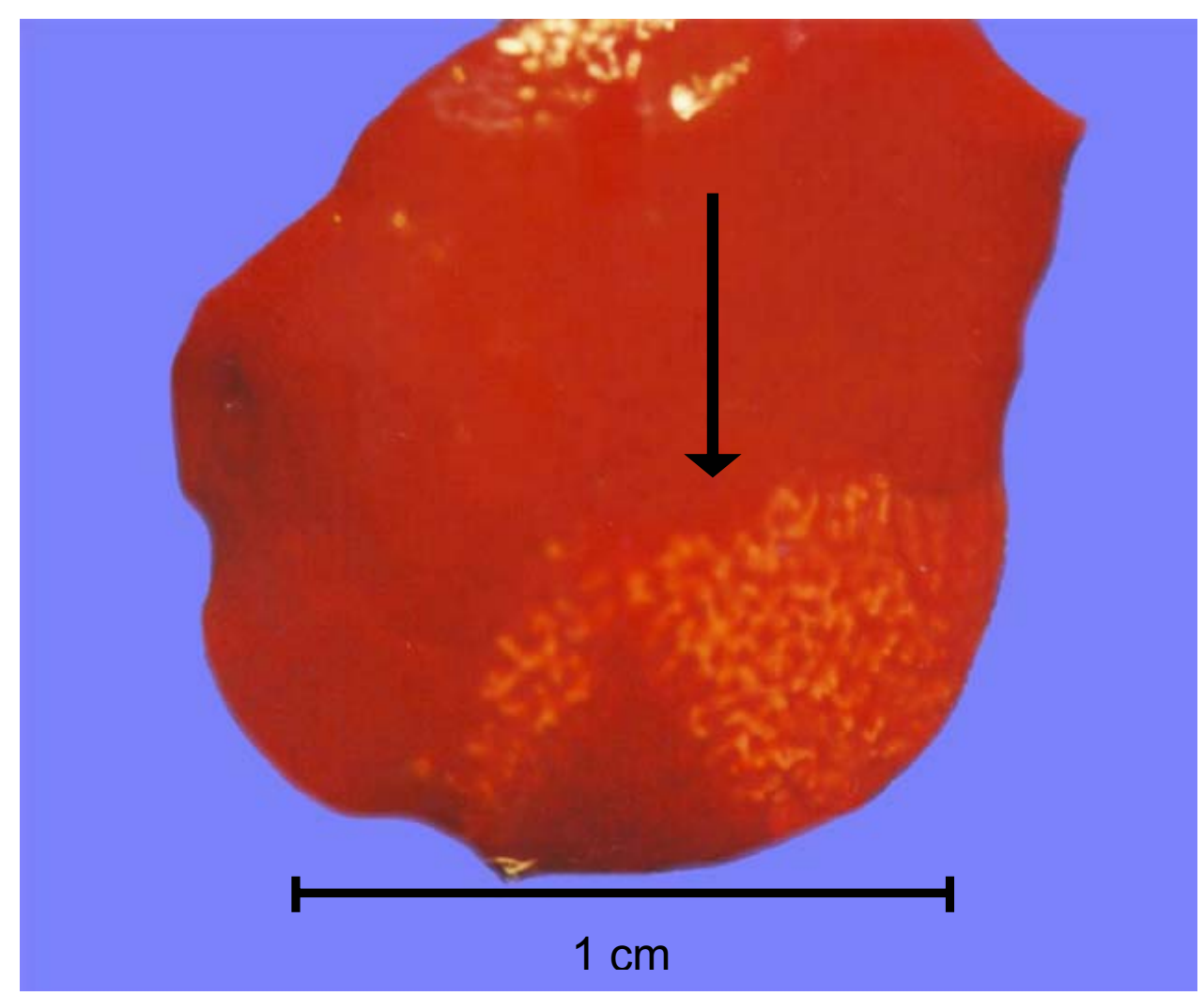

FIGURA 1 - Aspecto macroscópico do fígado de coelho decorridas 24 horas da injeção de solução de ácido acético 5\%. Notar a área branca-avermelhada correspondente à lesão (seta).

\section{Aspecto microscópico do figado}

O aspecto microscópico foi diferente entre o grupo tratado com solução salina (grupo A) e os grupos tratados com solução de ácido acetilsalicílico (grupo B e C) e de ácido acético (Grupo D e E) e estes entre si.

No grupo A (controle), evidenciou-se em dois animais pequena área de hemorragia intra-parenquimatosa, correspondente ao local de injeção, nos demais animais o fígado apresentava aspecto normal (Figura 2); nos demais grupos (B, C, D e E), foi observada, como característica comum em todos os animais, necrose coagulativa do parênquima hepático, bem delimitada, intensa e recente, pouco espalhada para adjacências e mais acentuada na área central. 


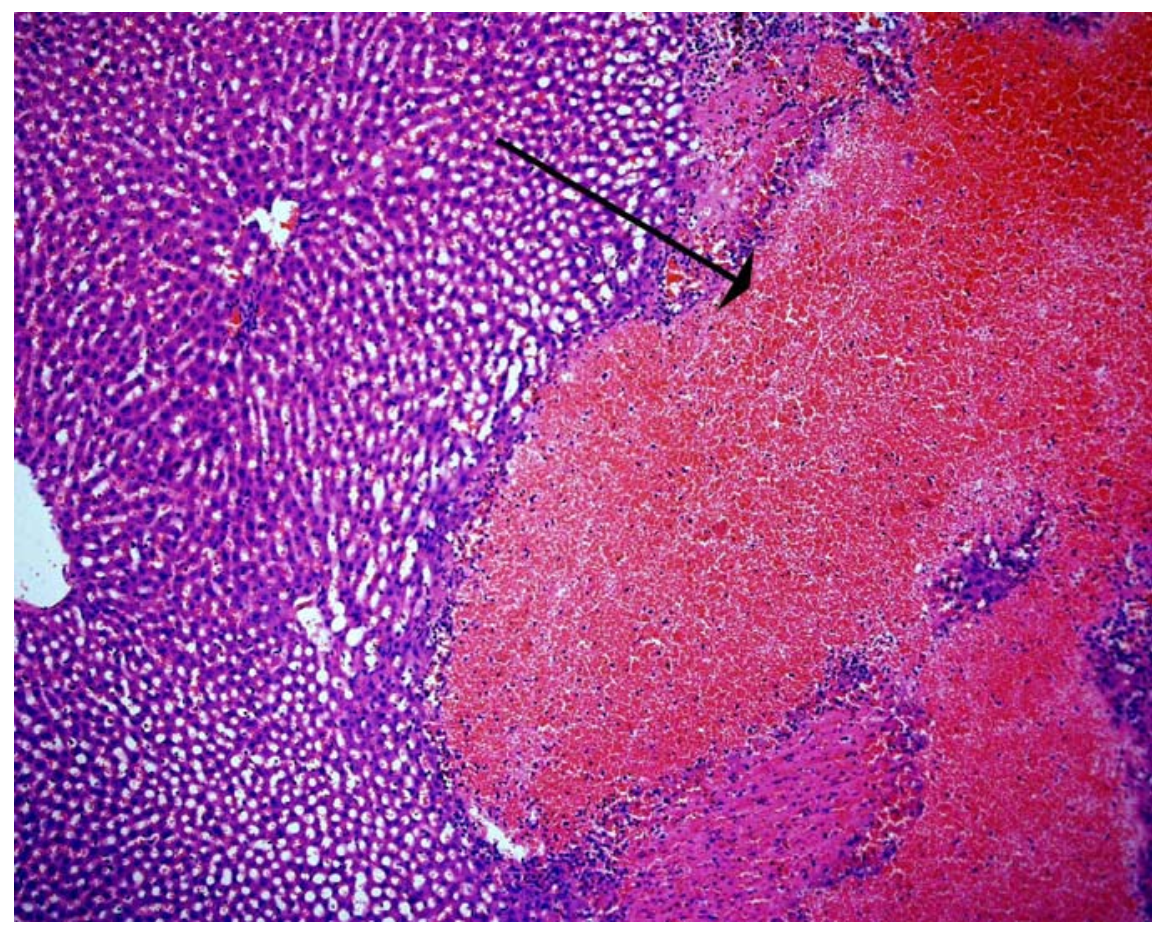

FIGURA 2 - Corte histológico do fígado de coelho decorridas 24 horas da injeção de solução salina. Área de hemorragia (seta) adjacente ao parênquima hepático normal. X100. Coloração HE

As características que diferenciaram os grupos tratados com ácido acetilsalicílico 2,5 e 5\% (Grupo B e C) dos animais do grupo tratado com ácido acético 2,5 e 5\% (Grupo D e E) foram a presença de infiltrado inflamatório localizado de forma difusa no meio da área de necrose e a presença de infiltrado inflamatório do tipo linfo histocitário e neutrofílico nos grupos tratados com ácido acetilsalicílico (Figura 3); enquanto que, nos grupos tratados com o ácido acético, o infiltrado inflamatório localizava-se na periferia, formando uma rima periférica, constituído principalmente por neutrófilos (Figura 4).

Não houve diferenças entre os animais tratados com as mesmas drogas e com concentrações diferentes (grupo B e C e grupo D e E).

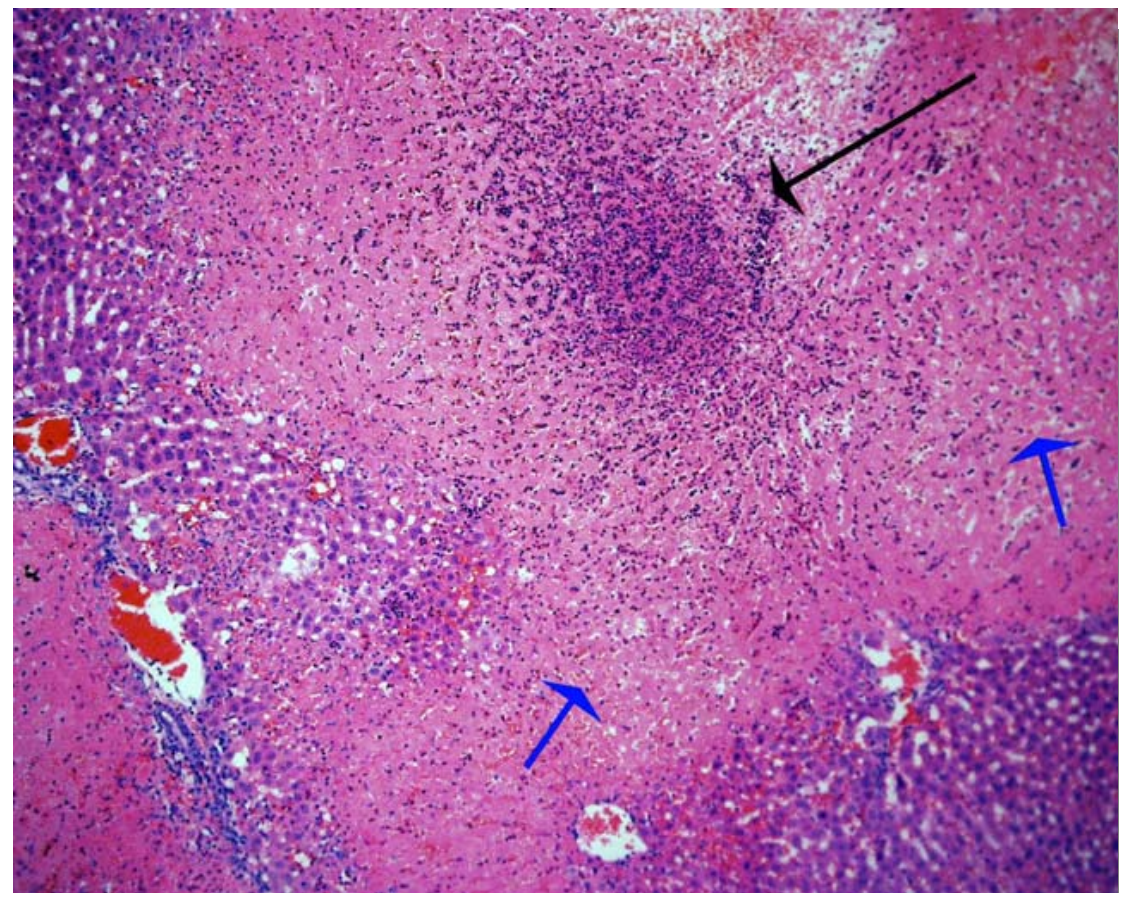

FIGURA 3 - Corte histológico do fígado de coelho decorridas 24 horas da injeção de solução de ácido acetilsalicílico 5\%. Área de necrose parenquimatosa (setas azuis) entremeada por infiltrado inflamatório linfohistiocitário - neutrofílico difuso (seta preta). X100. Coloração HE 


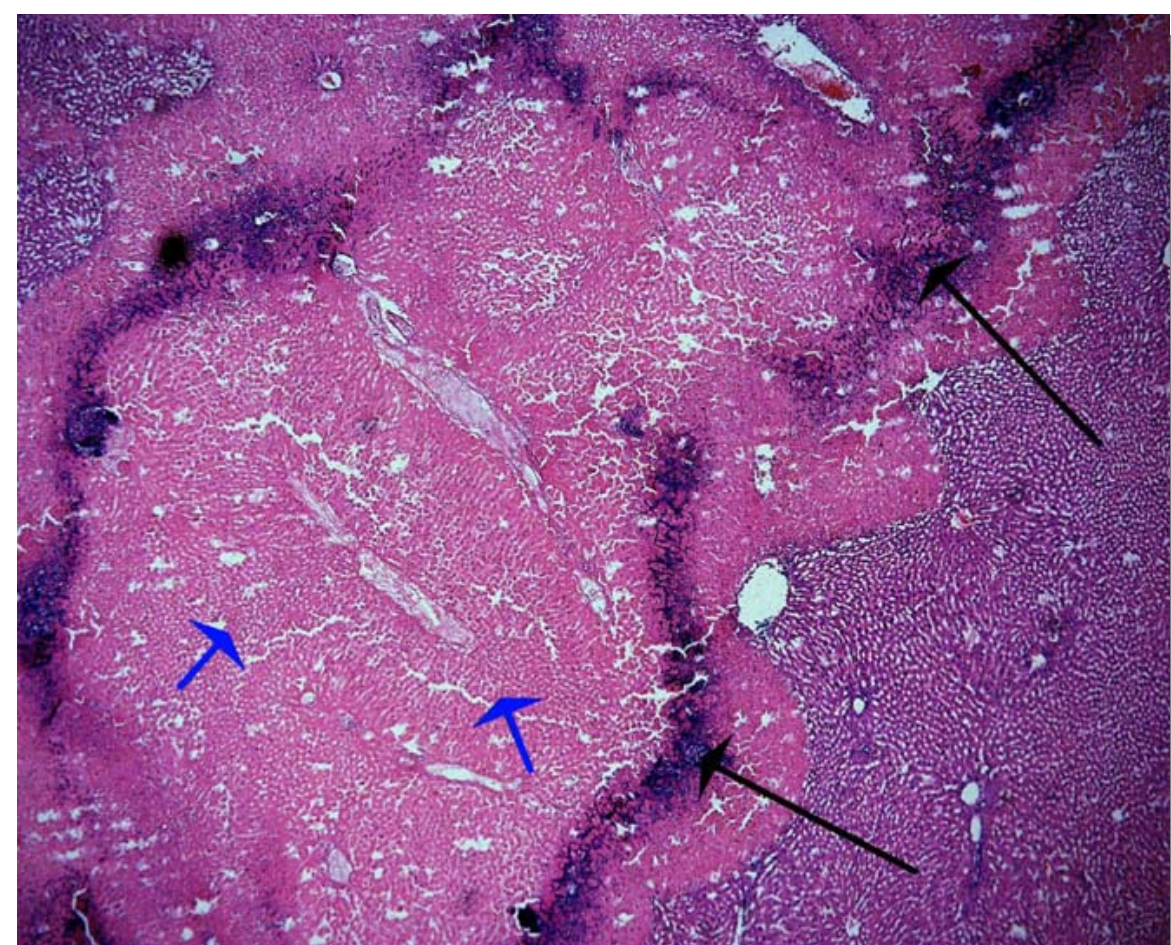

FIGURA 4 - Corte histológico do fígado de coelho decorridas 24 horas da injeção de solução de ácido acético 5\%. Área de necrose parenquimatosa (setas azuis) circundada por uma periferia de infiltrado inflamatório neutrofílico (setas pretas). X100. Coloração HE.

\section{PROTOCOLO 2}

\section{Evolução clínica}

Todos os animais apresentaram boa evolução clínica, não ocorrendo nenhum óbito.

\section{Evolução ponderal}

Não houve diferença estatisticamente significante em nenhum dos momentos estudados.

\section{Dosagens bioquímicas}

Glicemia, Gama Glutamiltransferase (GGT), Fosfatase Alcalina (FA), Aspartato Aminotransferase(AST) e Alanina Aminotransferase (ALT).

Todos os valores das dosagens de glicemia, gama-gt, fosfatse alcalina, aspartato aminotransferase e alanina aminotransferase estavam dentro dos valores de referência, não havendo diferença estatisticamente significante em nenhum das dosagens nos diferentes momentos estudados.
Aspectos macroscópicos da cavidade torácica e abdominal

Não se observaram quaisquer alterações na cavidade torácica dos animais nos 5 grupos deste protocolo.

O exame da cavidade abdominal no grupo tratado com solução salina (Grupo F) não evidenciou a presença de lesões hepáticas ou de outras alterações na cavidade.

Nos animais do grupo tratado com solução de ácido acetilsalicílico (2,5\%), a análise macroscópica do fígado revelou a presença de pequena lesão superficial, de colocação branca, levemente endurecida e delimitada, com diâmetro variável de 0,1 a 0,2 cm; nos animais tratados com solução de ácido acetilsalicílico 5\%, evidenciamos lesões semelhantes, de coloração branca, bem delimitada, circunscrita, endurecida, porém, comparativamente maior do que as do grupo anterior (AAS 2,5\%), com diâmetro variável de 0,3 a 0,4 cm (Figura 5). O restante da cavidade não apresentava alterações em ambos os grupos. 


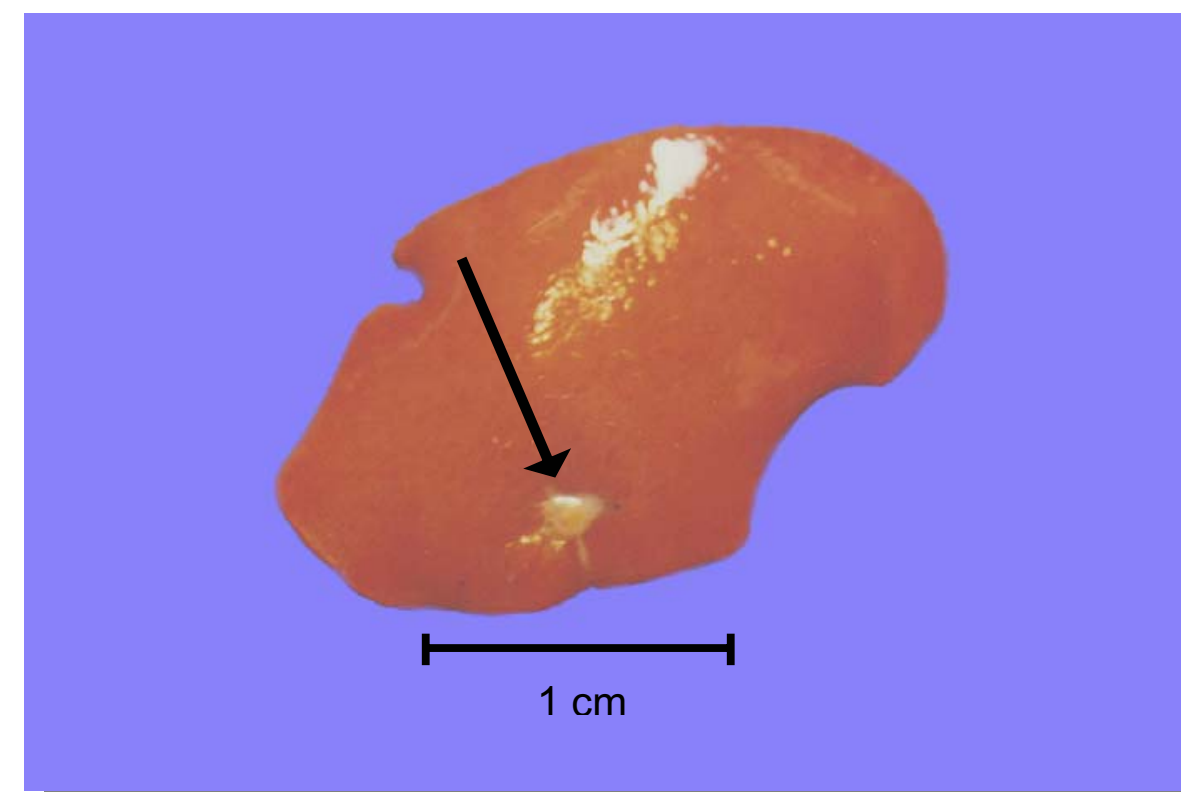

FIGURA 5 - Aspecto macroscópico do fígado de coelho decorridos 14 dias da injeção de solução de ácido acetilsalicílico 5\%. Notar área cicatricial (seta)

Quanto aos animais do grupo (I e J) tratado com solução de ácido acético (2,5 e 5\%), a análise do tecido hepático revelou lesão cicatricial de coloração branca, com limites precisos e endurecida, com diâmetro variável entre 0,4 e 0,6 $\mathrm{cm}$; esta característica de tamanho não apresentou diferença entre os dois grupos tratados com ácido acético (I e J), porém foi esta característica que os diferenciou do grupo tratado com solução de ácido acetilsalicílico ( $\mathrm{G} \mathrm{e} \mathrm{H})$. No restante da cavidade, não havia alterações (Figura 6).

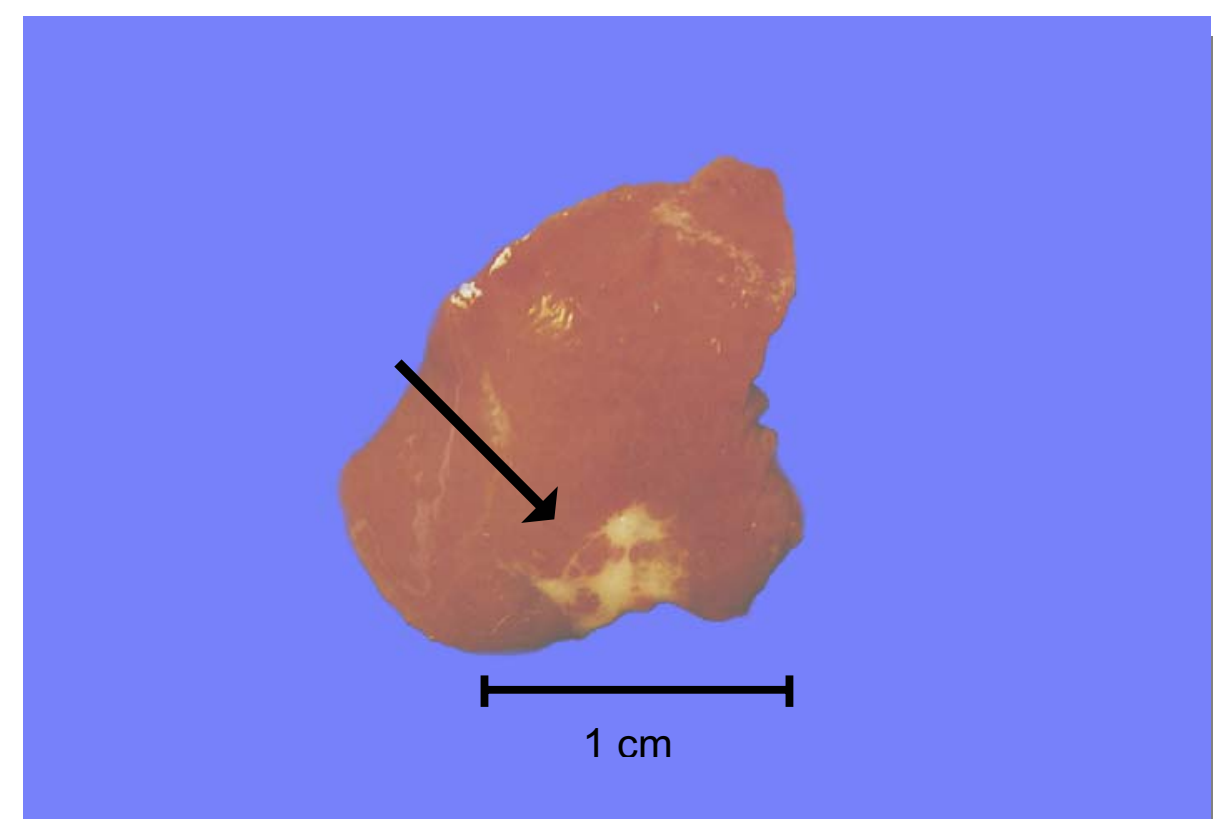

FIGURA 6 - Aspecto macroscópico do fígado de coelho decorridos 14 dias da injeção de solução de ácido acético 5\%. Área cicatricial (seta) 


\section{Aspectos microscópicos do fígado}

No grupo tratado com solução salina, não foi identificada nenhuma lesão/alteração anatomopatológica, fato este também observado no grupo tratado com solução de ácido acetilsalicílico a $2,5 \%$.

Observa-se que, no grupo tratado com solução de ácido acetilsalicílico (5\%), somente dois animais apresentaram alteração anatomopatológica, caracterizada por pequena área focal de cicatriz, associada à fibrose e deposição de colágeno e
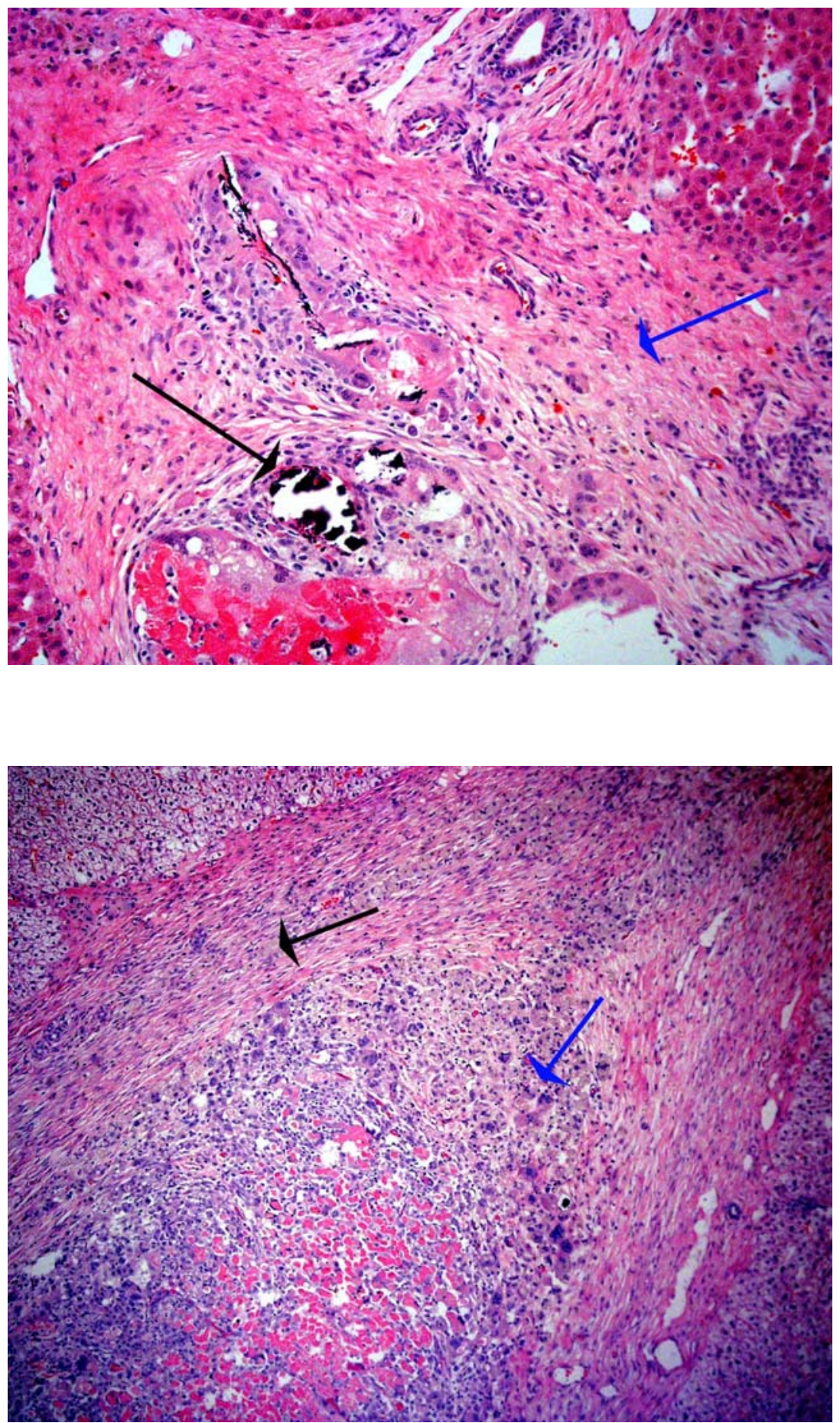

FIGURA 8 - Corte histológico do fígado de coelho decorridos 14 dias da injeção de solução de ácido acético 5\%. Área cicatricial com reação inflamatória do tipo corpo estranho (seta azul) com fibrose e deposição de colágeno (seta preta). X200. Coloração HE 


\section{Discussão}

Utilizamos $^{4}$ a solução composta por acido acetcio, glicerina e fenol no tratamento do tumor ascítico de Ehrlich; observamos que a solução in vitro destrói as células tumorais e in vivo reduz o número de células tumorais e eleva o número de células inflamatórias. Os resultados são dose dependentes. Observamos, porém, uma alta taxa de óbitos nos camundongos estudados; este fato foi atribuído à toxicidade das três drogas associadas em solução, pois todas, sabidamente, têm ação tóxica ${ }^{5}$

Assim, nos pareceu oportuno testar isoladamente um ou mais componentes desta solução em fígado de animais sadios. Verificamos em experiência piloto que, de fato, o ácido acético tem efeito destrutivo quando infiltrado no fígado.

Ocorreu-nos, a idéia de estudar também o efeito do ácido acetilsalicílico, para esta proposta existia embasamento: o componente acetil (a partir da observação do efeito lítico do ácido acético) e o componente salicílico (o ácido salicílico e os salicilatos são, tradicionalmente, empregados em uso externo como citolíticos).

Reforço altamente positivo foi fornecido pelos resultados do teste in vitro, ao se verificar a intensa ação citolítica da solução de ácido acetilsalicílico.

Protocolo 1 - Animais sem tumor - 24 horas após o tratamento

A evolução clínica e ponderal de todos os animais foi considerada boa, não evidenciando nenhum óbito. A ausência de mortalidade, boa evolução clínica e ponderal sugerem que as drogas utilizadas apresentam baixa ou nenhuma toxicidade, nas doses e concentrações utilizadas.

As dosagens de glicemia, fostase alcalina e gama-gt evidenciou que as taxas observadas encontravam-se dentro dos valores normais de referência, não havendo diferença estatisticamente significantes entre os tratamentos nos dois momentos. Esses resultados sugerem que as soluções utilizadas nas dosagens empregadas não interferem sobre o metabolismo glicídico sérico ou hepático, bem como não acarretam elevação das mesmas, apesar de causar lesões necróticas, ainda que bem localizadas.

Quanto às dosagens de AST e ALT nos dois momentos, verificou-se que os valores obtidos encontram-se dentro dos limites da normalidade e não há diferença estatisticamente significante entre os grupos nos dois momentos; houve, contudo, elevação nas dosagens em todos os grupos, inclusive no controle, após 24 horas. No que se refere a ALT, nota-se que há diferença estatisticamente significante entre os grupos tratados com ácido acético $(2,5 \%$ e $5 \%)$ e solução salina; não houve diferença entre os grupos tratados com solução de ácido acetilsalicílico $(2,5 \%$ e $5 \%$ ) e os demais grupos (salina e ácido acético). Como sabidamente as aminotransferases hepáticas elevam-se em geral após destruição celular, pode-se atribuir a elevação observada como decorrente da injeção hepática de soluções, sejam citolíticas ou não (soro fisiológico).

Quanto ao estudo anatomopatológico macroscópico das cavidades torácica e abdominal, não observamos alterações na cavidade torácica, seja na serosa, seja nos pulmões ou coração, em nenhum dos animais deste protocolo.

Quanto à cavidade abdominal, as únicas alterações observadas foram localizadas no fígado, restritas à zona de injeção; o restante da cavidade apresentava-se com aspecto normal. As alterações hepáticas ocorreram nos grupos tratados com solução de ácido acético ou ácido acetilsalicílico, e eram caracterizadas por áreas bem delimitadas e localizadas, com coloração branco-avermelhada correspondentes a áreas de necrose de coagulação do parênquima hepático na área infiltrada; no restante do parênquima, não havia nenhuma alteração.

Esses resultados demonstram claramente o efeito necrotizante da solução de ácido acético e do ácido acetilsalicílico, restrito à área de injeção hepática. Vale assinalar que OHNISH et al. ${ }^{6}$ observaram essas mesmas características de lesão utilizando ácido acético, porém em concentrações superiores $(10 \%-100 \%)$.

Não encontramos relato na literatura quanto ao uso do ácido acetilsalicílico com este propósito, de modo a poder comparar com nossos resultados.

Chamou-nos a atenção o fato do infiltrado inflamatório, na área de necrose, apresentar características diferentes entre as duas soluções: nos animais tratados com ácido acético, o infiltrado inflamatório delimitava a área de necrose na periferia, formando uma rima periférica, constituída predominantemente de neutrófilos, enquanto que, nos animais tratados com ácido acetilsalicílico, este infiltrado apresentava-se sob forma difusa e era constituído predominantemente por linfócitos e histiócitos. Estas diferentes características inflamatórias suscitam a hipótese de que o ácido acético teria efeito antiinflamatório local, impedindo o influxo de células inflamatórias para o centro da área necrosada.

Os resultados obtidos demonstraram que as soluções, nas dosagens empregadas, causam necrose localizada no tecido hepático, claramente evidente ao exame após 24 horas de tratamento, sem repercussões clínicas, bioquímicas e alterações patológicas extra-hepáticas demonstráveis.

Protocolo 2 - Animais sem tumor - 14 dias após o tratamento

Assim como no Protocolo 1, todos os animais apresentaram evolução clínica considerada boa, e em nenhum dos grupos houve óbito, confirmando assim que os efeitos das soluções em teste, nas dosagens empregas, são localizados no fígado e não acarretam repercussões sistêmicas evidentes pela avaliação clínica.

Quanto ao peso dos animais, todos evoluíram com aumento do peso, não sendo observada diferença estatística significante entre os grupos nos dois momentos; esta evolução ponderal favorável vem ao encontro da evolução clínica satisfatória e, conseqüentemente, fortalece a idéia de que as soluções utilizadas atuam de forma localizada, sem acarretar outras repercussões sistêmicas, evidenciáveis com a metodologia empregada. 
A análise das dosagens bioquímicas (glicemia, FA, GGT, AST e ALT) apresentou o mesmo perfil dos resultados observados no Protocolo 1: todos os valores estavam dentro da faixa de normalidade.

O estudo macroscópico da cavidade torácica, assim como nos animais do Protocolo 1, não evidenciou quaisquer alterações. A observação da cavidade abdominal revelou que nos animais do grupo controle o aspecto do fígado era normal e não havia outras alterações na cavidade. Pudemos observar uma pequena diferença entre os animais tratados com AAS $(2,5 \%$ e $5 \%)$ e AA $(2,5 \%$ e $5 \%)$, basicamente no tamanho da cicatriz observada no fígado, sendo esta mais evidente e um pouco maior nos grupos tratados com o AA. Esta diferença poderia ser atribuída ao poder necrotizante da solução de ácido acético, que embora não demonstre diferença na área de necrose após 24 horas, quando comparado ao AAS, acarretaria uma lesão mais intensa, causando área de cicatriz maior.

Como todos os animais tratados com AA $(2,5 \%$ e $5 \%)$ ou $\operatorname{AAS}(2,5 \%$ e $5 \%)$ apresentaram pequenas áreas macroscópicas de cicatriz, podemos inferir que estas soluções acarretam necrose ( 24 horas) e são seguidas de um processo cicatricial localizado (14 dias).

Estes achados macroscópicos foram confirmados pelo estudo microscópico. Notamos, novamente, que, nos animais tratados com AA (2,5\% e 5\%), havia focos de cicatrização, sendo que, no grupo que recebeu AA 2,5\%, os mesmos eram pequenos e superficiais, enquanto que, nos animais tratados com AA (5\%), a cicatriz era maior, com intenso processo inflamatório crônico do tipo corpo estranho, associado à calcificação e células gigantes.

\section{Conclusão}

Com base no modelo experimental, com a metodologia empregada e tendo em vista os objetivos estabelecidos, pudemos chegar às seguintes conclusões:

In vivo, nos animais sadios, ambas as soluções, quando injetadas no fígado acarretam, após 24 horas da injeção, a destruição localizada (necrose de coagulação); após 14 dias as lesões desaparecem ou são substituídas por discreto processo cicatricial (fibrose). Não foram observadas alterações clínicas. A única alteração bioquímica observada, foi a elevação da alanina aminotransferase (ALT) em todos os animais, tendo sido no entanto, estatisticamente significante apenas nos grupos tratados com ácido acético, decorridas 24 horas da injeção, mantendo-se, porém, dentro dos valores de referência.

\section{Referências}

1. World Health Organization-WHO. [on line]. Geneva, 1998. [cited $2001 \mathrm{Fev}$ 16]. Available from: URL: http:// www.who.org

2. Brasil. Ministério da Saúde. Datasus. Sistema de Informações sobre mortalidade, 1997. Brasília, 2001. [acesso em 2001 Fev 16]. Disponível em: URL: http://www.datasus.gov.br

3. Schlag PM, Benhidjeb T, Kilpert B. Surgical and multimodality treatment of colorectal liver metastases. Onkologie. 1999; 22:92-7.

4. Saad-Hossne, R. Efeitos da solução aquosa de fenol, ácido acético e glicerina sobre a celularidade no líquido ascítico do tumor de Ehrlich em camundongo [Dissertação de Mestrado]. Universidade Estadual Paulista - Faculdade de Medicina de Botucatu; 1997.

5. Saad-Hossne R, Hossne WS, Prado RG. Ascite neoplasica.Efeito da solução aquosa de fenol, acido acético e glicerina sobre o tumor ascitico de Ehrlich. Acta Cir Bras. 2003;18(6) :518-26.

6. Ohnishi K, Ohyama N, Ito S, Fujiwara K. Ultrasound guided intratumor injetion of acetic acid for the treatment of small hepatocellular carcinoma. Radiology. 1994; 193:743-52.

\section{Agradecimentos}

Prof. Dr. Carlos Eduardo Bacchi e Profa. Dra. Sheila Zambello de Pinho.

Correspondência:

Conflito de interesse: nenhum

Rogério Saad-Hossne

Departamento de Cirurgia e Ortopedia

Faculdade de Medicina de Botucatu-UNESP

18618-970 Botucatu - SP

saad@fmb.unesp.br

Recebimento: 03/09/2004

Revisão: 18/10/2004

Aprovação: 22/11/2004

\section{Como citar este artigo:}

Saad-Hossne R, Hossne WS, Prado RG. Efeito da solução de ácido acetilsalicílico e de ácido acético em fígado de coelhos. Acta Cir Bras. [serial online] 2004 Nov-Dez;19(6). Disponível em URL: http://www.scielo.br/acb [também em CD-ROM].

*Figuras coloridas disponíveis em www.scielo.br/acb 